\title{
PORTABLE HEATER AND REFRIGERATOR USING PELTIER MODULE
}

\author{
Pratik Wankhede \\ Department of Mechanical Engineering \\ GHRAET, Nagpur, Maharashtra, India
}

\begin{abstract}
Experimental study carried out with the application of thermoelectric generator under the benefits of society. TEG-12705 module is the key factor in our research study, which is based on peltier effect. One section of TEG gets cooled and provides refrigerating effect while other section becomes hot and rejects the heat to the environment. Our project is indirectly contributes to reduce pollution caused by CFCs and in the favour of reducing global warming also. Investigation carried out that instant cooling can be achieved with dual energy supply (i.e. solar and electrical). It is energy efficient, minimum cooling temperature $10-15^{\circ} \mathrm{C}$ and heating temperature $45-50^{\circ} \mathrm{C}$ can be achieved in this experimentation.
\end{abstract}

KEYWORDS - Portable refrigerator \& heater, Peltier effect, Thermoelectric effect, TEG

\section{INTRODUCTION}

In recent year, due to continuously increase in the global warming now a day' $s$ awareness of the alternative to reduce the effect of global warming has been increases. The set up is crucial process for many applications. It is ranging for store the beverages, foods and liquids storage purpose. It is also be used for the industrial, medical purpose like storing surgery work or keeping the medicines. Some refrigerator use compressor for cooling purpose and heating coil for heating purpose. This system is used the device which simultaneously cool and hot in the both side. The set up is portable, light weight, easy for maintenance, small in size with high durability. Nevertheless there is limitation of this system. The $\mathrm{COP}$ of peltier is less as compare to $\mathrm{COP}$ of refrigerator having gas compressor. The TEG is works on direct current electric source or on battery also.

M. Mirmanto et al. [1] concluded to know the effect of TE position on the cooler box performance by studying the thermoelectric cooler box with TE position. The cooling capacity of setup is decreased with time while the conduction heat transfer rate is increases. Which results the total heat transfer rate is decreased with respect to time. Mirmanto et al. [2] concluded for reducing the temperature of the cooling section with the help of heat sink fin-fan unit and double fan heat pipe unit. For the same paper he concluded that there is decrease in temperature of heat transfer rate of air with respect to time. Murat Gökçek et al.[3]This study investigated the thermal performance of thermoelectric refrigerator by studying the effect of Mini channel heat sink. If the water flow rate of the mini channel heat sink increases the inner temperature of the thermoelectric refrigerator decreases. The heat from the hot side of thermoelectric module is absorbed by mini channel heat sink. The study also shows that for achieving the high COP level of thermoelectric refrigerator by use of suitable heat sink.

This study concluded that the thermoelectric refrigerator is better alternative for conventional refrigeration system. By combining the TER with other with other refrigeration systems we can achieve better COP and temperature control. The total energy consumption reduces by using such type of hybrid systems and devices. This study can simplified by giving the example of combining VCR and TER systems which helps in reducing energy consumption.

\section{EXPERIMENTAL SETUP}

In this experimental setup we have two sections one is cold and another is hot. We are going to increase and decrease the temperature simultaneously with the help of peltier effects. We use four peltier modules of model no. TC-12706 made up of ceramic material. The body of hot and cold section is made up of transparent acrylic body. We are using acrylic body because it is heat resistance. The two hot and cold sections are placed in the black acrylic body box. The hot section gives more efficiency because we use aluminium casing as a heat exchanger. The two tabs are provided on the bottom of two sections from which the water is going to comes out. The whole setup is placed on the portable stand. The solar plate fixed on the upper side of the stand. In middle of the ply sheet the multimeter is fixed. On both side of the multimeter the thermocouples are fixed for measuring the temperature of the water inside the box. 


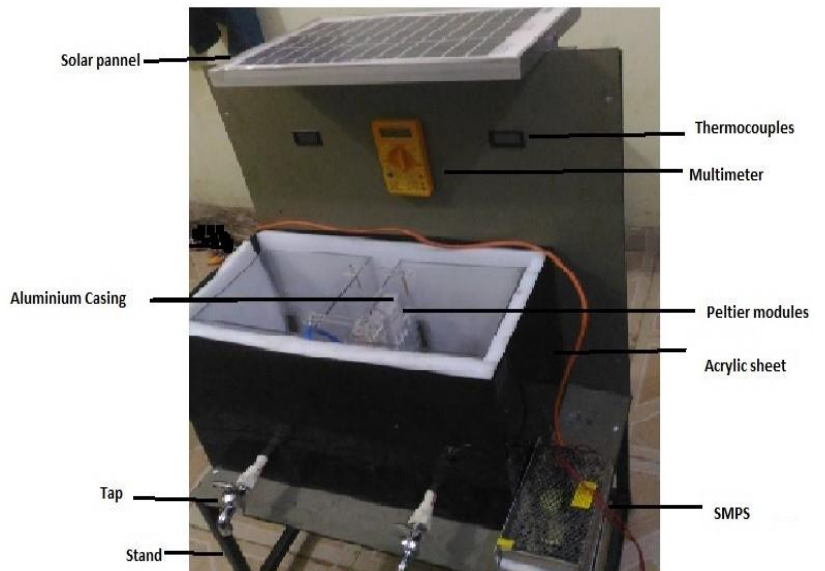

Fig1. Actual setup of Portable Heater \&Refrigerator

\section{EXPERIMENTAL PROCEDURE}

Entire setup with an electric supply ready for start. Then water poured into the both chamber and electricity is started. After 15 minutes we start to take readings with the help of thermocouples we take the readings of temperature in ${ }^{\circ} \mathrm{c}$. After that we take a reading from every 3 minutes (180 minutes). We take a reading for 4,6,8 litre resp. and for this readings we plot a graph for each case. We plot a graph with respect to Temperature Vs Time.

\section{RESULT AND DISCUSSION}

Hence we performed the experiment we get following results. Based on the experimental results we concluded that the if we require the more efficiency of setup the number of peltier modules should increase. The following are the results of experiment

1] For 4 litre at 4680 seconds we get temperature of heating side $39.9^{\circ} \mathrm{c}$ and in cooling side we get $25.8^{\circ} \mathrm{c}$.

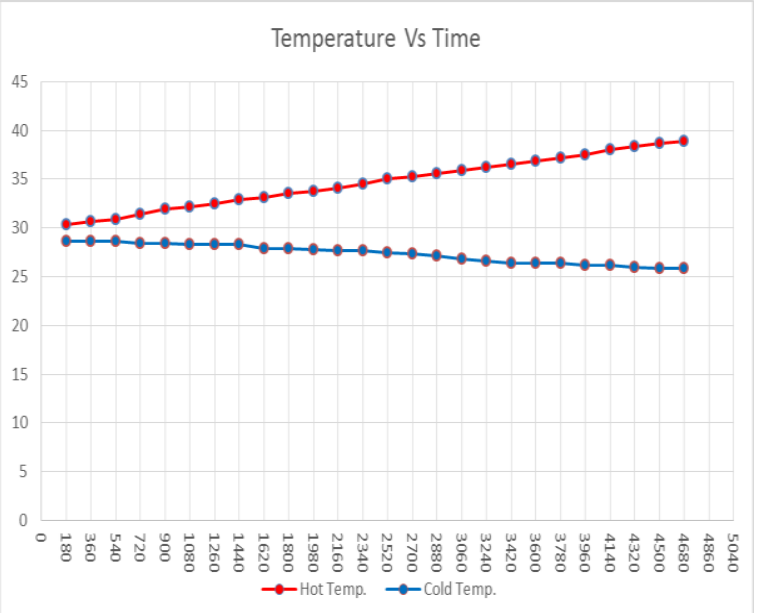

Fig2. Effect of Time on Temperature for 4 litre
2]For 6 litre at 4680 seconds we get temperature of heating side $39.9^{\circ} \mathrm{C}$ and in cooling side we get $25.8^{\circ} \mathrm{c}$.

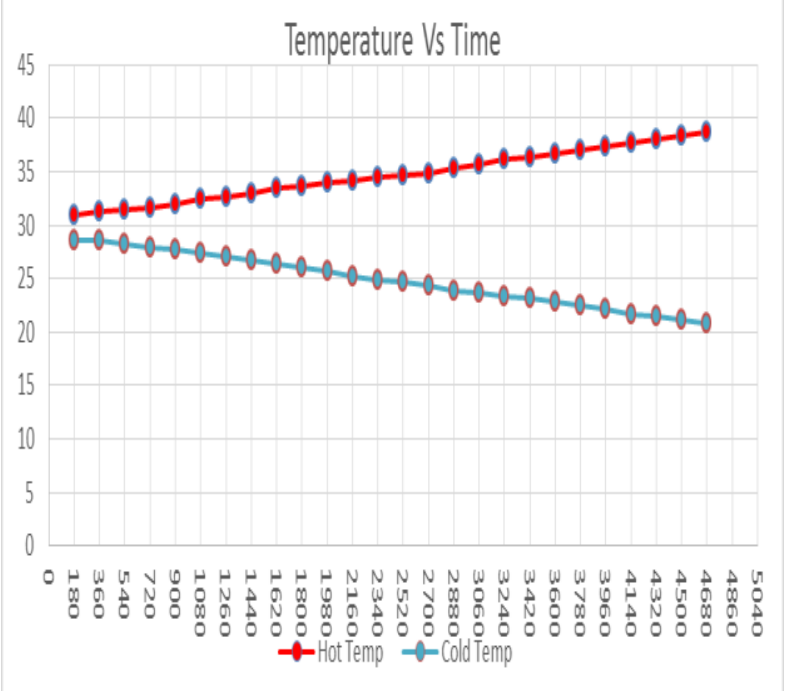

Fig3. Effect of Time on Temperature for 6 litre

3] For 8 litre at 4680 seconds we get temperature of heating side $38.1^{\circ} \mathrm{c}$ and in cooling side we get $22.1^{\circ} \mathrm{c}$.

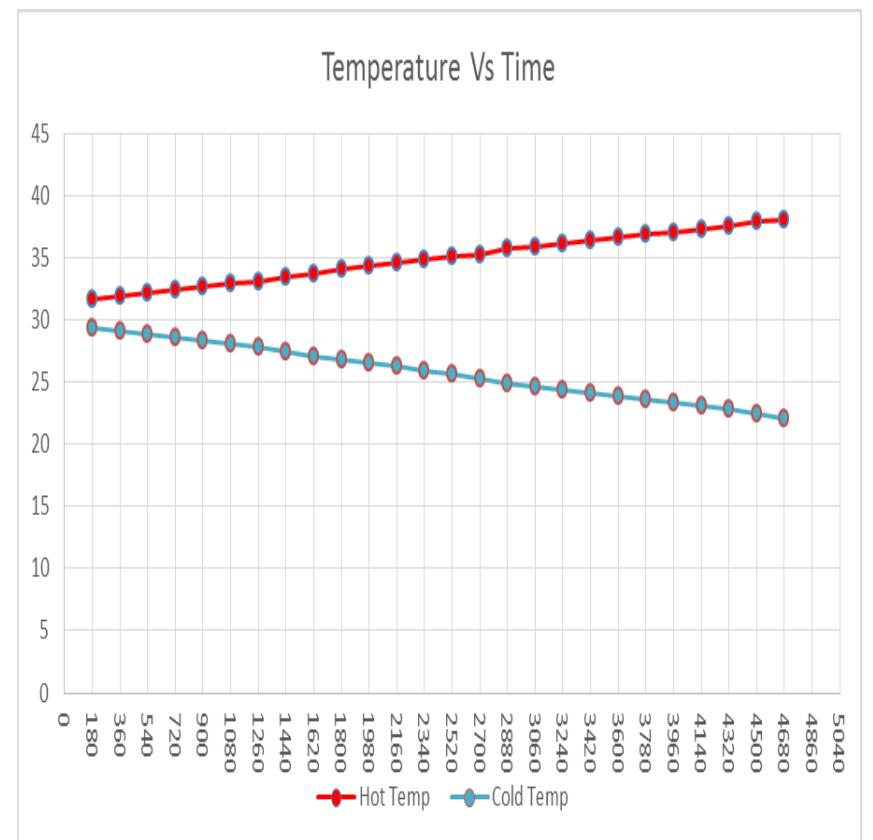

Fig4. Effect of Time on Temperature for 8 litre 


\section{International Journal of Engineering Applied Sciences and Technology, 2019 \\ Vol. 4, Issue 6, ISSN No. 2455-2143, Pages 155-157 \\ Published Online October 2019 in IJEAST (http://www.ijeast.com)}

4] For 6 litre at 3600 seconds for DC voltage we get temperature of heating side $37.3^{\circ} \mathrm{c}$ and in cooling side we get $25.1^{\circ} \mathrm{c}$.

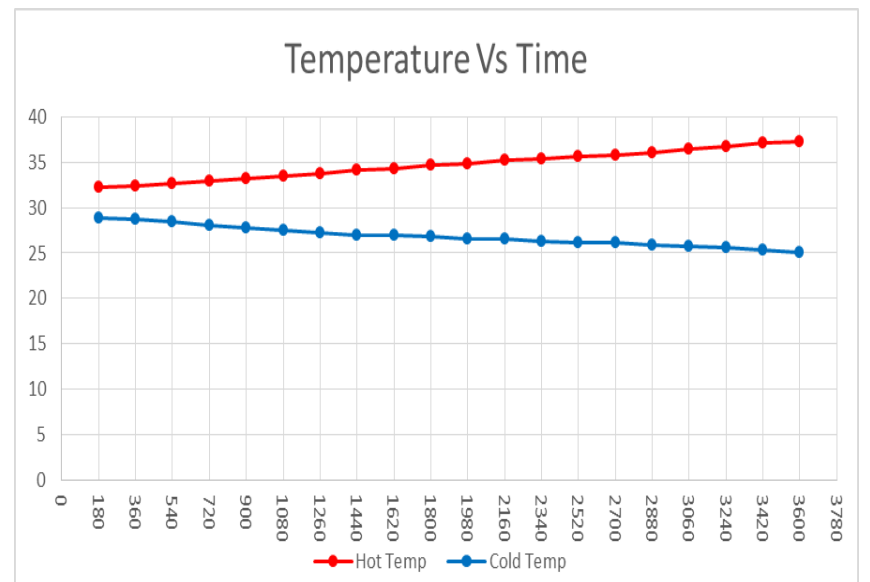

Fig5. Effect of Time on Temperature for 6 litre for DC supply

\section{CONCLUSION}

1) A graph shown temperature vs. time for indicates that the capacity of the system increases while the efficiency of the setup decreases in the heating section.

2) As per the requirement of more efficiency of setup the number of peltier modules should increases.

3) A graph also shows cooling effect between temperature and time which shows the fluctuation occurs in cooling section for increasing its capacity.

4)Comparatively study between DC supply and AC supply carried out and it is observed that the efficiency is greater in AC supply as compare in DC source.

\section{REFERENCES}

1) M. Mirmanto, S. Syahrul, YusiWirdan, Experimental performances of a thermoelectric cooler box with thermoelectric position variations- Engineering science and Technology, an international journal xxx (2018).

2) Prashant G. Sonkhede\&, Prof. A. K. Pathrikar, Portable Thermoelectric Refrigeration System for Medical Application- Computerand Communication Engineering Vol. 4, Issue 3, March 2016.

3) Prof. Rajendra. P. Patil, Thermoelectric Refrigerator Using Peltier Effect- Engineering Sciences \& Research Technology ISSN: 2277-9655.

4) Vivek Vaidya \& Samue Anvikar, Experimentation of Thermoelectric Refrigerator using Solar Energy for Cold Storage Application " Scientific Research \& Development Vol. 5, Issue 01, 2017 | ISSN (online): 2321-0613.
5) Martins Ozollapins, Aivars Kakitis, Thermoelectric generators as alternate energy source in the heating systemEngineering for rural development Jelgava, 24.-25.05.2012

6) Z.B. Tang, Y.D. Deng, A research on thermoelectric generator's electrical performance under temperature mismatch conditions for automotive waste heat recovery systemCase Studies in Thermal Engineering5(2015)143150 